\title{
Genetic Update on Auditory Neuropathy
}

\author{
S. Marlin ${ }^{a, b} \quad$ L. Jonard ${ }^{a, c} \quad$ N. Loundon ${ }^{d} \quad$ C. Bonnet ${ }^{a}$ \\ N. Leboulanger ${ }^{d}$ L. Van Maldergem ${ }^{e}$ S. Gherbi ${ }^{b}$ M. Louha ${ }^{a, c}$ \\ P. Deltenre ${ }^{g}$ J.L. Collette ${ }^{f}$ R. Couderc ${ }^{a, c}$ E.N. Garabedian ${ }^{a, d}$ \\ F. Denoyelle ${ }^{a, d}$
}

aINSERM UMRS587, Hôpital Trousseau, bService de Génétique, Centre des Maladies Rares, 'Service de Biochimie et Biologie Moléculaire et d'Service d'ORL, Hôpital Trousseau, Assistance Publique, Hôpitaux de Paris, Paris, et ${ }^{e}$ Service de Génétique, Centre de Référence, et ${ }^{f}$ Service d'ORL, Centre Hospitalier Intercommunal Créteil, Créteil, France; 9 Département de Neurologie, Hôpital Brugmann, Bruxelles, Belgique

\section{Key Words}

Auditory brainstem evoked responses $\cdot$ Auditory neuropathy $\cdot$ Genetics $\cdot$ Hearing impairment • Otoacoustic emission

\section{Abstract}

Auditory neuropathy (AN) is defined as a sensorineural hearing impairment (HI) characterized by preserved cochlear outer hair cell function with normal otoacoustic emissions but abnormal or absent brainstem evoked potentials. The prevalence of AN in HIs remains to be established and its pathophysiology has not been determined. Several environmental and genetic causes have been identified, but the majority of cases remain unexplained. In the last 10 years, many genes have been identified in isolated and/or syndromic HI. Some of them (OTOF, PJVK, DIAPH3, OPA1, FXN, PMP22, ERCC6, ERCC8, SLC19A2 and TIMM8A, for example) are responsible for phenotypes corresponding to the AN definition. This review will focus on isolated and syndromic forms of AN for which the causative genes have been identified.

Copyright $\odot 2011$ S. Karger AG, Basel

\section{Introduction}

Genetic hearing impairment (HI) is divided into two main categories: nonsyndromic $\mathrm{HI}$, which accounts for the vast majority of cases (90\%), and syndromic HI (10\%), including $>500$ different disorders. Recent works in human genetics indicate that in developed coun- 
tries, $60-80 \%$ of congenital deafness cases have a genetic cause [Fraser, 1964; Marazita et al., 1993]. Both syndromic and nonsyndromic HIs are generally monogenic disorders, but with a large genetic heterogeneity. To date, 50 loci have been identified for nonsyndromic autosomal dominant HI and 65 for recessive HI [Petit, 2006]. Estimations suggest that $>250$ genes for each syndromic and nonsyndromic inheritance mode may be involved, meaning that a majority remains to be identified. Therefore, genetic deafness covers a vast set of rare disorders generally described in a single family.

Once infectious and toxic fetal disorders are excluded, syndromic $\mathrm{HI}$ is usually a genetic disorder. The first edition of Gorlin and Pindborg's [1964] reference work Syndromes of the Head and Neck, published in 1964, described less than a hundred distinct disorders including HI as one of the signs. The latest edition, the 5th edition of Gorlin's Syndromes of the Head and Neck (Oxford Monographs on Medical Genetics), published in 2010, includes $450 \mathrm{HI}$ syndromes and additional clinical features that can affect virtually any organ [Hennekam et al., 2010]. Over the last decade, genes responsible for several hundreds of syndromic forms of $\mathrm{HI}$ have been localized to human chromosomes, and $>100$ have been identified.

Auditory neuropathy (AN), initially defined in 1996 by Starr et al. [1996], describes an HI characterized by normal otoacoustic emissions (OAEs) associated with abnormal or absent click-evoked auditory brainstem responses (ABRs). AN patients present with mild-toprofound uni- or bilateral HI. The localization of the lesion can range from inner hair cell (HC) synapses (synaptopathy) to the spiral ganglion (neuropathy). Cochlear microphonic potentials can differentiate inner ear and nerve defects, but this technique is rarely used in clinical practice. The precise prevalence of $\mathrm{AN}$ in $\mathrm{HI}$ patients ranges from 1 to $>5 \%$ according to different studies [Lotfi and Mehrkian, 2007; Rodríguez Domínguez et al., 2007; Wang et al., 2007]. Both environmental factors (prematurity, low birth weight, infection during pregnancy, or hyperbilirubinemia) and genetic causes have already been associated with AN [Foerst et al., 2006; Beutner et al., 2007].

Three reviews have been published about genetics and AN [Kaga and Starr, 2009; Santarelli, 2010; Manchaiah et al., 2011]. The possible mechanisms underlying both the alteration of auditory nerve discharge for mutations in individual genes and a better understanding of the genetic pathophysiological basis for this disorder were discussed in these reviews.

This complementary study will focus on both nonsyndromic and syndromic forms of AN for which the causative genes have been identified in humans.

\section{Nonsyndromic ANs}

\section{Autosomal Recessive Inheritance}

OTOF, encoding otoferlin, was the first gene (OMIM 603681) identified in an HI associated with AN [Varga et al., 2003]. The recessive deafness associated with OTOF had previously been localized to chromosome 2p23.1 and named DFNB9 (OMIM 601017). This nonsyndromic bilateral congenital severe-to-profound deafness is characterized by initially preserved OAEs without recordable ABRs. No malformation was revealed by magnetic resonance imaging or temporal bone computerized tomography scans. However, OAEs disappear with time and electrophysiological testing is consistent with a cochlear defect. More than 50 pathogenic OTOF mutations have already been reported [Rodríguez-Ballesteros et al., 2008; Romanos et al., 2009; Chiu et al., 2010; Wang et al., 2010; Zadro et al., 2010]. Two recurrent mutations were described, one nonsense mutation (p.Q829X) [Migliosi et al., 2002] and one missense mutation (p.E1700Q) [Chiu et al., 2010]. The p.Q829X mutation, which replaces the glutamine residue at position 829 by a premature termination codon, was found in $3 \%$ of nonsyndromic profound prelingual HI in Spain [Rodríguez-Ballesteros et al., 2003, 2008]. 
The missense mutation (p.E1700Q) was predominantly identified in Taiwanese patients [Chiu et al., 2010]. In adult mice, otoferlin is expressed both in cochlear and vestibular HCs. In the organ of Corti, otoferlin is strongly expressed in cochlear inner HCs and weakly in the outer HCs during the early stages of embryonic development. Later on, no expression is detected in outer HCs. Indeed, normal OAEs are transmitted despite a profound auditory deficit. Within the inner HCs, otoferlin plays a role in the exocytosis of synaptic vesicles released to the afferent synapse [Roux et al., 2006]. Three transgenic models of otoferlin-deficient mice have been developed, one by engineered knockout and two others by N-ethyl N-nitrosourea mutagenesis to deactivate the functional domains of the protein [Roux et al., 2006; Longo-Guess et al., 2007; Pangrsic et al., 2010]. Affected mice present with profound bilateral deafness and preserved OAEs. Auditory nerves respond to direct electrical stimulation, thus indicating that the afferent neuronal auditory system has been preserved. Hence, patients carrying OTOF mutations present a HC synaptopathy. The DFNB9-linked auditory deficit is in the cochlear region, which is corroborated by performances after cochlear implantation similar to other implanted children [Rodríguez-Ballesteros et al., 2003; Rouillon et al., 2006]. It was noted that OTOF is also mutated in patients affected with temperaturesensitive nonsyndromic recessive AN [Varga et al., 2006; Romanos et al., 2009; Marlin et al., 2010; Wang et al., 2010].

The gene PJVK encoding pejvakin (OMIM 610219), which is deficient in DFNB59, has been localized on chromosome 2q31.1-q31.3 and identified (OMIM 610220). Homozygous mutations co-segregating with the disease have been first identified in two consanguineous Iranian families [Delmaghani et al., 2006]. The two families came from the same geographically isolated region of Iran. Affected subjects all present with nonsyndromic sensorineural profound prelingual HI. In one family, affected individuals presented with profound deafness involving all frequencies. For the second one, pure-tone audiometry in affected subjects showed flat audiograms with hearing levels characteristic of severe HI. ABR records were unavailable for 6 patients affected by profound deafness, while in the 6 other patients (severe $\mathrm{HI}$ with flat curves), ABR thresholds were $80-100 \mathrm{~dB}$ with an increase in wave V latency (the only wave that could be identified). OAEs were present in 11 of the 12 patients. An in-depth clinical characterization could not be conducted for two remaining families. Both homozygous pejvakin mutations identified were missense mutations. In three families, the mutation resulted in the substitution of an arginine residue by a tryptophan residue at position 183 (p.R183W). In the fourth family, the mutation involved a threonine at position 54 that was replaced by an isoleucine (p.T54I). The p.R183W mutation was also found in a Turkish family [Collin et al., 2007]. Surprisingly, for this patient, ABRs and OAEs were absent (contrary to the 3 Iranian patients), suggesting that the function of outer $\mathrm{HC}$ is distorted [Collin et al., 2007]. Genetic and/or environmental factors may play a role to explain this discrepancy. Indeed, the functional role of pejvakin remains unknown. A transgenic mouse was created with the p.R183W mutation in order to test its pathogenicity. All homozygous mutant mice developed moderate HI. Their ABRs were characterized by reduced amplitude and increased latency for all waves. These anomalies were generally found equally across the whole spectrum of recorded frequencies, and sometimes exclusively in the midrange frequencies. All mutant mice had OAEs. No vestibular anomalies could be identified. The auditory deficit remained stable over time. Ultrastructural analysis (electron microscopy) of the cochlea revealed no anomalies. A more recent study revealed that pejvakin expression was limited to the cochlea, spiral ganglion, vestibule and the first three relays of the auditory pathway. Therefore, pejvakin appeared to be the first protein involved in a nonsyndromic form of retrocochlear AN. Recently, homozygous pejvakin mutations have been identified in two consanguineous families (a deletion in an Iranian family and an insertion in a Moroccan family) [Ebermann et al., 2007]. In the Iranian family, HI progressed from moderate to profound. 


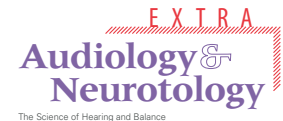

\begin{tabular}{l}
\hline \begin{tabular}{l} 
Audiol Neurotol Extra 2011;1:20-29 \\
\hline DOI: 10.1159/000329545
\end{tabular} \\
$\begin{array}{l}\text { Published online: November 5, 2011 S. Karger AG, Basel } \\
\text { www.karger.com/aue }\end{array}$ \\
\hline Marlin et al.: Auditory Neuropathy Reviewed
\end{tabular}

Unfortunately, no ABRs or OAEs were available for these patients. In the Moroccan family, HI was progressive with a cochlear origin. Indeed, the authors reported moderate-to-profound deafness with no OAEs, nonrecordable ABRs and absence of microphonic potentials. Functional tests also suggested a central vestibular disorder in deaf patients. Another murine model of a pejvakin disorder has been reported recently [Schwander et al., 2007]. 'Sirtaki' mice carried a homozygous point mutation that introduces an $\mathrm{A} \rightarrow \mathrm{T}$ transversion leading to a premature stop codon at amino acid 290 (p.K290X). These mice presented with profound progressive bilateral deafness. The authors reported that the auditory deficit was localized in both cochlear and afferent neurons. OAEs were absent, although increased ABR wave latencies were noted without ultrastructural defects. Thus, different mutations in the same gene can lead to heterogeneous phenotypes.

\section{Mitochondrial Inheritance}

Mitochondrial defects can be identified in both syndromic and nonsyndromic deafness. The common feature of these radically different expression patterns of the same mutation is the mitochondrial or 'maternal' mode of inheritance. In fact, it is the genotype that is inherited (the mitochondrial mutation), since the phenotype will depend on several factors, including heteroplasmy (the variable proportion of mitochondrial DNA mutated between two tissues). The m.1095T $\rightarrow$ C (T1095C) mutation was identified in a Chinese patient presenting with nonsyndromic AN beginning in his twenties. Speech discrimination was more strongly altered than the hearing level. Moderate bilateral perception HI, nonrecordable ABRs and conserved OAEs were observed in this patient [Wang et al., 2005]. Complete clinical examination did not reveal any other neurological disorder.

The mitochondrial m.1095T $\rightarrow$ C mutation had also been reported in a family where AN was associated with neurological disorders (Parkinson's disease and neuropathy) [Thyagarajan et al., 2000]. In conclusion, mitochondrial mutations can lead to pure AN but, depending on the mutation, AN can be associated with other progressive clinical signs which should be systematically screened.

\section{Autosomal Dominant Inheritance}

A linkage study carried out in a large American family of European descent suggested the existence of an autosomal dominant nonsyndromic AN. The locus was mapped to chromosome 13q14-q21 [Kim et al., 2004]. Average age at onset was 19 years. All affected members of the family were compound heterozygous for the locus, except for 2 homozygous individuals whose parents were consanguineous. However, no apparent clinical features differentiated their phenotype from that of the compound heterozygotes, except for an earlier age at onset ( 8 and 9 years compared to 19 years, respectively) [Kim et al., 2004]. The PCDH9 gene, located in the AUNA1 candidate interval, was not found to be responsible for autosomal dominant AN [Grati et al., 2009]. The corresponding gene, named AUNA1, has been characterized recently. Indeed, a mutation in the DIAPH3 gene is responsible for AUNA1 [Schoen et al., 2010]. One mutation was found in a highly conserved region of the $5^{\prime}$-untranslated region $(\mathrm{c} .-172 \mathrm{G} \rightarrow \mathrm{A})$. This mutation seems to upregulate DIAPH3 expression.

\section{Major Syndromic ANs}

\section{An Example of Autosomal Recessive Inheritance}

Friedreich's ataxia (OMIM 229300) is one of the most common forms of autosomal recessive ataxia. Frataxin (FXN), the deficient protein, is encoded by the FXN gene located on chromosome 9q13. Friedreich's ataxia is the only neurodegenerative disorder caused by expanded 
triplet repeats (GAA triplets) in the homozygous state. Initial diagnosis is based on clinical data and criteria established by Harding [1981]: autosomal recessive inheritance, clinical signs appearing before 25 years of age, progressive distal ataxia, loss of myotatic reflexes and electrophysiological signs of axonal neuropathy. This progressive disorder may also include dysarthria, absent deep tendon reflexes, loss of vibrational and proprioceptive sensation, and pyramidal signs. Later on, cardiomyopathy sets in, which differentiates it from other types of ataxia. Less frequently, deafness, optic atrophy and glucose intolerance or diabetes may occur. Various kinds of vestibular disorders have also been reported [Ell et al., 1984].

HI is present in around 7-8\% of cases [López-Díaz-de-León et al., 2003]. The severity of HI can range from moderate to profound; can be either uni- or bilateral, and is predominantly affecting low frequencies. The deficit is generally progressive. AN could be present with abnormal ABRs associated with conserved OAEs. Despite few alterations in tone audiometry, patients complain of poor auditory discrimination, particularly in noisy environments. The ABRs demonstrated a severe dysfunction involving the cochlear nerve and brainstem since the early stages of disease. Some reports proposed that the absence of recordable ABRs in certain cases may be due to desynchronization of the cochlear nerve fibers. As suggested by the neurological pathophysiology of the disease, the lesion usually starts at the spiral ganglion and spreads towards the proximal auditory nerve clusters. Neuropathological studies have revealed neuronal loss in the cochlear nucleus, the spiral ganglion and the superior olivary nucleus. Some authors have also used 'vestibular neuropathy' to define the heterogeneous signals recorded in vestibular tests [Fujikawa and Starr, 2000].

\section{A Genetically Heterogeneous Example (Dominant Recessive and Dominant X-Linked Inheritance)}

Charcot-Marie-Tooth disease (CMT) is the most common inherited neuropathy and also the most heterogeneous one ( $>50$ different nerve genetic disorders and 35 identified genes). The main autosomal dominant form is due to the duplication of a $1.5-\mathrm{Mb}$ chromosomal segment on chromosome 17 (CMT1a; OMIM 118220). This segment contains the gene encoding the PMP22 myelin protein, and its overexpression (3 copies instead of 2 ) causes extensive demyelination of the peripheral nerves specifically associated with CMT1a. This major form accounts for $>70 \%$ of autosomal dominant CMTs. The severity of symptoms is highly variable. Patients can present with a progressive paresis of the lower limbs, generally beginning in late adolescence, steppage gait while walking and peroneal muscular atrophy. CMT is progressive, possibly spreading to the upper limbs in the later stages. Patients also experience shooting pain that can become paroxysmal. Approximately $3 \%$ of the patients become wheel chair bound. Hearing loss is not rare and can occur later on [Azzedine et al., 2003; Senderek et al., 2003].

Mutations in the $P 0$ or $M P Z$ gene encoding another myelin protein, located on chromosome 1q22 (OMIM 159440), are also implicated in a similar dominant polyneuropathy. A third relatively homologous, $\mathrm{X}$-linked dominant form has been attributed to mutations in the GJB1 gene encoding connexin 32 (OMIM 302800). Sensorineural HI was associated with polyneuropathies in both CMT1a and other CMT types [Verhagen et al., 2005]. Finally, another autosomal recessive disorder was found in a Slovenian Roma (Gypsy) kindred originating from Bulgaria, Hungary and Romania. In this form, HI starts before adolescence, whereas in classical CMT the deafness sets in later (CMT-Lom; OMIM 601455) [Butinar et al., 1999]. The severity of the HI varies from mild to profound, depending on the family and the patient's age. The HI affects speech comprehension out of proportion to the pure tone loss. Present OAEs are sometimes associated with nonrecordable or highly altered ABRs. Progressive deafness in a $M P Z$ mutation carrier family was the first sign of CMT disease, preceding signs of peripheral neuropathy $>10$ years [Seeman et al., 2004]. 


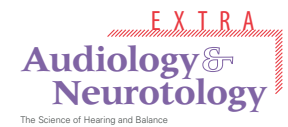

Audiol Neurotol Extra 2011;1:20-29

DOI: 10.1159/000329545

Published online: November 5, 2011

Marlin et al.: Auditory Neuropathy Reviewed
๔ 2011 S. Karger AG, Basel

www.karger.com/aue

\section{An Example of a Dominant Disorder}

Autosomal dominant optic atrophy (OMIM 165500) is characterized by a progressive decline in visual acuity and a loss of color vision. Onset usually occurs between 4 and 6 years. Dilated fundus examination showed optic nerve pallor. OPA1, the gene mapping to $3 \mathrm{q} 28$, is responsible for most autosomal dominant optic atrophy cases. More than 60 different $O P A 1$ mutations have been identified. OPA1 encodes a mitochondrial dynamin-related protein which is thought to play a key role in the balance between mitochondrial fusion and fission events. It appears that the OPA 1 missense mutation $\mathrm{p} . \mathrm{R} 445 \mathrm{H}$ may be associated with early-onset sensorineural deafness ( $<10$ years old), ptosis and ophthalmoplegia, in addition to the classically observed optic atrophy [Amati-Bonneau et al., 2005]. HI is progressive and may be asymmetrical. Audiological tests leaned towards an AN with preserved OAEs and nonrecordable ABRs, or both desynchronized ABRs and OAEs. Word discrimination is essentially more altered than the level of $\mathrm{HI}$ identified through tone audiometry testing would suggest. In the guinea pig inner ear, OPA1 is localized in sensory and neural cells, suggesting cochlear and spiral ganglion impairments. In 1 Japanese patient with a mutation in the OPA1 gene, vestibular dysfunction was reported [Mizutari et al., 2010]. This observation suggests that vestibular evaluation should be performed in AN patients carrying the OPA1 mutation.

\section{Other Syndromic Forms}

More recently, one nonsense mutation in the TMEM126A gene, found in a consanguineous Algerian family, caused autosomal recessive optic atrophy and AN [Meyer et al., 2010]. Patients present with normal OAEs but abnormal ABRs. Similarly, 2 cases of Leber's hereditary optic neuropathy with AN have been reported [Ceranić and Luxon, 2004]. However, in both cases, it would be only an uncommon finding [Yu-Wai-Man et al., 2008]. Numerous loci implicated in syndromic deafness remain uncharacterized. Differentiating cochlear from central deafness and 'genuine' AN with auditory nerve disorders may be difficult. Syndromes affecting the central nervous system can affect cochlear and retrocochlear functions either concomitantly or successively. The three following examples illustrate the diversity in lesion sites.

Cockayne syndrome (OMIM 216400) is a rare multisystemic autosomal recessive disorder characterized by early postnatal growth retardation with a background of premature aging of many organs. Patients present with early progeroid facial features (emaciated face/eyes sunk deep in the orbit) together with progressive microcephaly, cataract with retinitis pigmentosa, photosensitivity and HI. Interindividual variability has also been observed. Two genes, CSA (ERCC8) located on chromosome 5q12.1 and CSB (ERCC6) located on chromosome 10q11.23, are involved in the Cockayne syndrome. Both genes are implicated in DNA replication. They trigger the cell to apoptosis by altering the DNA replication process. Chromosome breaks can be detected following UV irradiation. In half of Cockayne syndrome patients, HI is reported [Gandolfi et al., 1984]. However, the exact site of HI has not been clearly identified yet. ABRs are always abnormal. Postmortem neuropathological investigations have highlighted both peripheral (cochlear neuroepithelium and spiral ganglion) and central (damage to all three auditory nuclei) disease. The authors suggested a potential central synaptic atrophy secondary to peripheral degeneration. Differentiating AN from central deafness is complex, even in the presence of neuropathological data.

The Mohr-Tranebjaerg syndrome (OMIM 304700) was initially reported as the first nonsyndromic X-linked recessive deafness (DFN-1). However, the deafness was later shown to be part of a progressive syndrome that included visual disability leading to cortical blindness, abnormal dystonia-type movements and other neurological signs, such as spastic paraparesis, fractures, and mental retardation or dementia [Tranebjaerg et al., 1992]. Deafness usually occurs early in life, during the prelingual or early postlingual period [Binder et al., 
2003]. The Mohr-Tranebjaerg syndrome is caused by mutation in the TIMM8A (DDP) gene. The DDP protein is localized in the mitochondrial intermembrane space, promoting mitochondrial protein import of certain precursors. Bahmad et al. [2007] described for the first time the Mohr-Tranebjaerg syndrome as a true AN. In 1 Norwegian family, all 4 affected patients carried the p.Q38fsX64 mutation. ABRs showed mixed cochlear and retrocochlear pathology, while OAEs tended to be absent. PET scans highlighted a decreased metabolism in the cortical temporal areas and basal ganglia. In conclusion, AN associated with syndromic deafness can coexist with an apparently intact cochlear structure.

Linkage analysis in a Chinese family identified a locus responsible for X-linked recessive AN and diffuse peripheral neuropathy, AUNX1, mapped to Xq23-27.3 [Wang et al., 2006]. The degree of HI varied from mild to severe with diminution of OAEs and absence of ABRs from disease onset. More recently, $A Q P 3$ was no longer regarded responsible for X-linked recessive inheritance [Liu et al., 2010].

\section{Conclusion}

The examples outlined above illustrate the exceptionally variable nature of AN, where genetically determined ANs remain exceptional diseases. Most of them are syndromic and often associate with other neurological disorders that should therefore be screened on a routine basis. An in-depth clinical characterization of hereditary HI will almost certainly lead to the rapid identification of new syndromic and nonsyndromic ANs.

\section{Acknowledgments}

We thank Amanda McClelland for her critical revision of the paper. This work was supported by the 'GIS-Institut des maladies rares' and the French association 'S'entendre'.

\section{Disclosure Statement}

The authors declare that they have no conflicts of interest.

\section{References}

Amati-Bonneau P, Guichet A, Olichon A, Chevrollier A, Viala F, Miot S, Ayuso C, Odent S, Arrouet C, Verny C, Calmels M-N, Simard G, Belenguer P, Wang J, Puel J-L, Hamel C, Malthièry Y, Bonneau D, Lenaers G, Reynier P: OPA1 R445H mutation in optic atrophy associated with sensorineural deafness. Ann Neurol 2005;58:958-963.

Azzedine H, Ruberg M, Ente D, Gilardeau C, Périé S, Wechsler B, Brice A, LeGuern E, Dubourg O: Variability of disease progression in a family with autosomal recessive CMT associated with a S194X and new R310Q mutation in the GDAP1 gene. Neuromuscul Disord 2003;13:341-346.

Bahmad F Jr, Merchant SN, Nadol JB Jr, Tranebjaerg L: Otopathology in Mohr-Tranebjaerg syndrome. Laryngoscope 2007;117:1202-1208.

Beutner D, Foerst A, Lang-Roth R, von Wedel H, Walger M: Risk factors for auditory neuropathy/auditory synaptopathy. ORL J Otorhinolaryngol Relat Spec 2007;69:239-244.

Binder J, Hofmann S, Kreisel S, Wöhrle JC, Bäzner H, Krauss JK, Hennerici MG, Bauer MF: Clinical and molecular findings in a patient with a novel mutation in the deafness-dystonia peptide (DDP1) gene. Brain 2003;126:1814-1820. 
Butinar D, Zidar J, Leonardis L, Popovic M, Kalaydjieva L, Angelicheva D, Sininger Y, Keats B, Starr A: Hereditary auditory, vestibular, motor, and sensory neuropathy in a Slovenian Roma (Gypsy) kindred. Ann Neurol 1999;46:36-44.

Ceranic B, Luxon LM: Progressive auditory neuropathy in patients with Leber's hereditary optic neuropathy. J Neurol Neurosurg Psychiatry 2004;75:626-630.

Chiu YH, Wu CC, Lu YC, Chen PJ, Lee WY, Liu AY, Hsu CJ: Mutations in the OTOF gene in Taiwanese patients with auditory neuropathy. Audiol Neurootol 2010;15:364-374.

Collin RW, Kalay E, Oostrik J, Caylan R, Wollnik B, Arslan S, den Hollander AI, Birinci Y, Lichtner P, Strom TM, Toraman B, Hoefsloot LH, Cremers CWRJ, Brunner HG, Cremers FPM, Karaguzel A, Kremer H: Involvement of DFNB59 mutations in autosomal recessive nonsyndromic hearing impairment. Hum Mutat 2007;28:718-723.

Delmaghani S, del Castillo FJ, Michel V, Leibovici M, Aghaie A, Ron U, Van Laer L, Ben-Tal N, Van Camp G, Weil D, Langa F, Lathrop M, Avan P, Petit C: Mutations in the gene encoding pejvakin, a newly identified protein of the afferent auditory pathway, cause DFNB59 auditory neuropathy. Nat Genet 2006;38:770-778.

Ebermann I, Walger M, Scholl HP, Charbel Issa P, Lüke C, Nürnberg G, Lang-Roth R, Becker C, Nürnberg P, Bolz HJ: Truncating mutation of the DFNB59 gene causes cochlear hearing impairment and central vestibular dysfunction. Hum Mutat 2007;28:571-577.

Ell J, Prasher D, Rudge P: Neuro-otological abnormalities in Friedreich's ataxia. J Neurol Neurosurg Psychiatry 1984;47:26-32.

Foerst A, Beutner D, Lang-Roth R, Huttenbrink K-B, von Wedel H, Walger M: Prevalence of auditory neuropathy/synaptopathy in a population of children with profound hearing loss. Int J Pediatr Otorhinolaryngol 2006;70:1415-1422.

Fraser GR: Profound childhood deafness. J Med Genet 1964;38:118-151.

Fujikawa S, Starr A: Vestibular neuropathy accompanying auditory and peripheral neuropathies. Arch Otolaryngol Head Neck Surg 2000;126:1453-1456.

Gandolfi A, Horoupian D, Rapin I, DeTeresa R, Hyams V: Deafness in Cockayne's syndrome: morphological, morphometric, and quantitative study of the auditory pathway. Ann Neurol 1984;15:135-143.

Gorlin RJ, Pindborg JJ, McKusick VA: Syndromes of the Head and Neck. New York, McGraw-Hill, 1964.

Grati FR, Lesperance MM, De Toffol S, Chinetti S, Selicorni A, Emery S, Grimi B, Dulcetti F, Malvestiti B, Taylor J, Milani S, Ruggeri AM, Maggi F, Simoni G: Pure monosomy and pure trisomy of 13q21.231.1 consequent to a familial insertional translocation: exclusion of PCDH9 as the responsible gene for autosomal dominant auditory neuropathy (AUNA1). Am J Med Genet 2009;149A:906-913.

Harding AE: Friedreich's ataxia: a clinical and genetic study of 90 families with an analysis of early diagnostic criteria and intrafamilial clustering of clinical features. Brain 1981;104:589-620.

Hennekam R, Allanson J, Krantz I: Gorlin's Syndromes of the Head and Neck. Oxford Monographs on Medical Genetics, ed 5. New York, Oxford University Press, 2010, p 1520.

Kaga K, Starr A: Neuropathies of the Auditory and Vestibular Eighth Cranial Nerves. Tokyo, Springer, 2009.

Kim TB, Isaacson B, Sivakumaran TA, Starr A, Keats BJB, Lesperance MM: A gene responsible for autosomal dominant auditory neuropathy (AUNA1) maps to 13q14-21. J Med Genet 2004;41:872-876.

Liu Q, Han DY, Ji YB, Li JQ, Lan L, Zhao C, Wang QJ: Analyzing GRIA3 gene mutations located in AUNX1 locus in a Chinese pedigree with auditory neuropathy (in Chinese). Xi Bao Yu Fen Zi Mian Yi Xue Za Zhi 2010;26:376-378.

Longo-Guess C, Gagnon LH, Bergstrom DE, Johnson KR: A missense mutation in the conserved C2B domain of otoferlin causes deafness in a new mouse model of DFNB9. Hear Res 2007;234:21-28.

Lopez-Diaz-de-Leon E, Silva-Rojas A, Ysunza A, Amavisca R, Rivera R: Auditory neuropathy in Friedreich ataxia. A report of two cases. Int J Pediatr Otorhinolaryngol 2003;67:641-648.

Lotfi Y, Mehrkian S: The prevalence of auditory neuropathy in students with hearing impairment in Tehran, Iran. Arch Iran Med 2007;10:233-235.

Manchaiah VK, Zhao F, Danesh AA, Duprey R: The genetic basis of auditory neuropathy spectrum disorder (ANSD). Int J Pediatr Otorhinolaryngol 2011;75:151-158.

Marazita ML, Ploughman LM, Rawlings B, Remington E, Arnos KS, Nance WE: Genetic epidemiological studies of early-onset deafness in the U.S. school-age population. Am J Med Genet 1993;46:486-491. 
Marlin S, Feldmann D, Nguyen Y, Rouillon I, Loundon N, Jonard L, Bonnet C, Couderc R, Garabedian EN, Petit C, Denoyelle F: Temperature-sensitive auditory neuropathy associated with an otoferlin mutation: deafening fever! Biochem Biophys Res Commun 2010;394:737-742.

Meyer E, Michaelides M, Tee LJ, Robson AG, Rahman F, Pasha S, Luxon LM, Moore AT, Maher ER: Nonsense mutation in TMEM126A causing autosomal recessive optic atrophy and auditory neuropathy. Mol Vis 2010;16:650-664.

Migliosi V, Modamio-Hoybjor S, Moreno-Pelayo MA, Rodríguez-Ballesteros M, Villamar M, Tellería D, Menéndez I, Moreno F, Del Castillo I: Q829X, a novel mutation in the gene encoding otoferlin (OTOF), is frequently found in Spanish patients with prelingual non-syndromic hearing loss. J Med Genet 2002;39:502-506.

Mizutari K, Matsunaga T, Inoue Y, Kaneko H, Yagi H, Namba K, Shimizu S, Kaga K, Ogawa K: Vestibular dysfunction in a Japanese patient with a mutation in the gene OPA1. J Neurol Sci 2010;293:23-28.

Pangrsic T, Lasarow L, Reuter K, Takago H, Schwander M, Riedel D, Frank T, Tarantino LM, Bailey JS, Strenzke N, Brose N, Müller U, Reisinger E, Moser T: Hearing requires otoferlin-dependent efficient replenishment of synaptic vesicles in hair cells. Nat Neurosci 2010;13:869-876.

Petit C: From deafness genes to hearing mechanisms: harmony and counterpoint. Trends Mol Med 2006; 12:57-64

Rodriguez Dominguez FJ, Cubillana Herrero JD, Canizares Gallardo N, Pérez Aguilera R: Prevalence of auditory neuropathy: prospective study in a tertiary-care center (in Spanish). Acta Otorrinolaringol Esp 2007;58:239-245.

Rodriguez-Ballesteros M, del Castillo FJ, Martin Y, Moreno-Pelayo MA, Morera C, Prieto F, Marco J, Morant A, Gallo-Terán J, Morales-Angulo C, Navas C, Trinidad G, Tapia MC, Moreno F, del Castillo I: Auditory neuropathy in patients carrying mutations in the otoferlin gene (OTOF). Hum Mutat 2003; 22:451-456.

Rodriguez-Ballesteros M, Reynoso R, Olarte M, Villamar M, Morera C, Santarelli R, Arslan E, Medá C, Curet C, Völter C, Sainz-Quevedo M, Castorina P, Ambrosetti U, Berrettini S, Frei K, Tedín S, Smith J, Cruz Tapia M, Cavallé L, Gelvez N, Primignani P, Gómez-Rosas E, Martín M, Moreno-Pelayo MA, Tamayo M, Moreno-Barral J, Moreno F, del Castillo I: A multicenter study on the prevalence and spectrum of mutations in the otoferlin gene (OTOF) in subjects with nonsyndromic hearing impairment and auditory neuropathy. Hum Mutat 2008;29:823-831.

Romanos J, Kimura L, Favero ML, Izarra FAR, de Mello Auricchio MTB, Batissoco AC, Lezirovitz K, Abreu-Silva RS, Mingroni-Netto RC: Novel OTOF mutations in Brazilian patients with auditory neuropathy. J Hum Genet 2009;54:382-385.

Rouillon I, Marcolla A, Roux I, Marlin S, Feldmann D, Couderc R, Jonard L, Petit C, Denoyelle F, Garabédian EN, Loundon N: Results of cochlear implantation in two children with mutations in the OTOF gene. Int J Pediatr Otorhinolaryngol 2006;70:689-966.

Roux I, Safieddine S, Nouvian R, Grati M, Simmler M-C, Bahloul A, Perfettini I, Le Gall M, Rostaing P, Hamard G, Triller A, Avan P, Moser T, Petit C: Otoferlin, defective in a human deafness form, is essential for exocytosis at the auditory ribbon synapse. Cell 2006;127:277-289.

Santarelli R: Information from cochlear potentials and genetic mutations helps localize the lesion site in auditory neuropathy. Genome Med 2010;2:91.

Schoen CJ, Emery SB, Thorne MC, Ammana HR, Sliwerska E, Arnett J, Hortsch M, Hannan F, Burmeister M, Lesperance Marci M: Increased activity of diaphanous homolog 3 (DIAPH3)/diaphanous causes hearing defects in humans with auditory neuropathy and in Drosophila. Proc Natl Acad Sci USA 2010;107:13396-13401.

Schwander M, Sczaniecka A, Grillet N, Bailey JS, Avenarius M, Najmabadi H, Steffy BM, Federe GC, Lagler EA, Banan R, Hice R, Grabowski-Boase L, Keithley EM, Ryan AF, Housley GD, Wiltshire T, Smith Richard JH, Tarantino LM, Müller U: A forward genetics screen in mice identifies recessive deafness traits and reveals that pejvakin is essential for outer hair cell function. J Neurosci 2007;27: 2163-2175.

Seeman P, Mazanec R, Huehne K, Suslíková P, Keller O, Rautenstrauss B: Hearing loss as the first feature of late-onset axonal CMT disease due to a novel P0 mutation. Neurology 2004;63:733-735. 
Senderek J, Bergmann C, Stendel C, Kirfel J, Verpoorten N, De Jonghe P, Timmerman V, Chrast R, Verheijen MHG, Lemke G, Battaloglu E, Parman Y, Erdem S, Tan E, Topaloglu H, Hahn A, Müller-Felber W, Rizzuto N, Fabrizi GM, Stuhrmann M, Rudnik-Schöneborn S, Züchner S, Michael Schröder J, Buchheim E, Straub V, Klepper J, Huehne K, Rautenstrauss B, Büttner R, Nelis E, Zerres K: Mutations in a gene encoding a novel SH3/TPR domain protein cause autosomal recessive Charcot-MarieTooth type 4C neuropathy. Am J Hum Genet 2003;73:1106-1119.

Starr A, Picton TW, Sininger Y, Hood LJ, Berlin CI: Auditory neuropathy. Brain 1996;119(Pt 3):741-753.

Thyagarajan D, Bressman S, Bruno C, Przedborski S, Shanske S, Lynch T, Fahn S, DiMauro S: A novel mitochondrial 12SrRNA point mutation in parkinsonism, deafness, and neuropathy. Ann Neurol 2000;48:730-736.

Tranebjaerg L, Lou H, Andresen J: New X-linked syndrome with apraxia, ataxia, and mental deficiency: clinical, cytogenetic and neuropsychological studies in two Danish families. Am J Med Genet 1992; 43:498-504.

Varga R, Avenarius MR, Kelley PM, Keats BJ, Berlin CI, Hood LJ, Morlet TG, Brashears SM, Starr A, Cohn ES, Smith RJH, Kimberling WJ: OTOF mutations revealed by genetic analysis of hearing loss families including a potential temperature sensitive auditory neuropathy allele. J Med Genet 2006;43:576581.

Varga R, Kelley PM, Keats BJ, Starr A, Leal SM, Cohn E, Kimberling WJ: Non-syndromic recessive auditory neuropathy is the result of mutations in the otoferlin (OTOF) gene. J Med Genet 2003;40:45-50.

Verhagen WI, Huygen PL, Gabreels-Festen AA, Engelhart M, van Mierlo PJWB, van Engelen BGM: Sensorineural hearing impairment in patients with Pmp22 duplication, deletion, and frameshift mutations. Otol Neurotol 2005;26:405-414.

Wang DY, Wang YC, Weil D, Zhao YL, Rao SQ, Zong L, Ji YB, Liu Q, Li JQ, Yang HM, Shen Y, BenedictAlderfer C, Zheng QY, Petit C, Wang QJ: Screening mutations of OTOF gene in Chinese patients with auditory neuropathy, including a familial case of temperature-sensitive auditory neuropathy. BMC Med Genet 2010;11:79.

Wang J, Bu X, Zhou A, Xing G, Shi Q: Auditory neuropathy in deaf school students (in Chinese). Lin Chung Er Bi Yan Hou Tou Jing Wai Ke Za Zhi 2007;21:457-459.

Wang Q, Li R, Zhao H, Peters JL, Liu Q, Yang L, Han D, Greinwald JH Jr, Young WY, Guan MX: Clinical and molecular characterization of a Chinese patient with auditory neuropathy associated with mitochondrial 12S rRNA T1095C mutation. Am J Med Genet A 2005;133:27-30.

Wang QJ, Li QZ, Rao SQ, Lee K, Huang XS, Yang WY, Zhai SQ, Guo WW, Guo YF, Yu N, Zhao YL, Yuan H, Guan J, Leal SM, Han DY, Shen Y: AUNX1, a novel locus responsible for X linked recessive auditory and peripheral neuropathy, maps to Xq23-27.3. J Med Genet 2006;43:e33.

Yu-Wai-Man P, Elliott C, Griffiths PG, Johnson IJ, Chinnery PF: Investigation of auditory dysfunction in Leber hereditary optic neuropathy. Acta Ophthalmol 2008;86:630-633.

Zadro C, Ciorba A, Fabris A, Morgutti M, Trevisi P, Gasparini P, Martini A: Five new OTOF gene mutations and auditory neuropathy. Int J Pediatr Otorhinol 2010;74:494-498. 